\title{
INOVAÇÕES NA PRODUÇÃO E COMERCIALIZAÇÃO DE CACHAÇA ARTESANAL: ESTUDO DE CASO DE UM ALAMBIQUE DO NORTE DE MINAS GERAIS
}

Alex Fernando Borges ${ }^{1}$

Brenda Silva Queiroz ${ }^{1}$

Alessandro Gomes Enoque ${ }^{1}$

Juliane Silvestre ${ }^{1}$

${ }^{1}$ Universidade Federal de Uberlândia 


\section{INOVAÇÕES NA PRODUÇÃO E COMERCIALIZAÇÃO DE CACHAÇA ARTESANAL: ESTUDO DE CASO DE UM ALAMBIQUE DO NORTE DE MINAS GERAIS}

Resumo: O objetivo deste trabalho consistiu em identificar a construção de inovações em uma organização do setor de cachaça artesanal, situada no Norte de Minas Gerais. Especificamente, buscou-se recuperar a história da empresa e averiguar as diferentes inovações radicais e incrementais que se manifestam no alambique, com foco nas práticas de produção e comercialização de cachaça. Para tanto, foi efetuado um estudo de caso de natureza qualitativa, estruturado por meio da realização de entrevistas junto ao empreendedor fundador e gestores do negócio. Os resultados permitiram identificar o desenvolvimento de inovações radicais, como a produção artesanal da cachaça em escala industrial, a criação de novos produtos e de estratégias de marketing e de envelhecimento da bebida, e de inovações incrementais, como melhorias no processo produtivo e de comercialização, na redução da graduação alcoólica da cachaça, e no foco em qualidade através da melhoria contínua em seus produtos e processos.

Palavras-chave: Empreendedorismo. Inovação. Inovação Radical. Inovação Incremental.

\section{$1 \quad$ Introdução}

A inovação, e todo processo a ela vinculado, é tida comumente como um fator importante para o desenvolvimento econômico e para a competitividade empresarial. Diversas organizações implementam práticas inovadoras, visando a geração de valor, o estabelecimento de diferenciais no mercado, a criação de novos produtos e serviços, bem como o desenvolvimento de produtos, métodos e processos já explorados pela empresa. Neste cenário, a inovação passa a se configurar como um elemento relevante no contexto organizacional, e, consequentemente, um importante objeto de estudos e pesquisas no campo da administração e economia.

O Manual de Oslo (2005) aponta a existência de diversas definições para o tema inovação. Na literatura da área, é possível observar que a inovação tem sido associada à geração ou criação de novos produtos, serviços, processos, métodos de produção, técnicas e tecnologias, geralmente voltadas para a promoção de melhorias internas ou externas à empresa (Freitas, Filardi, Lott \& Braga, 2017). Com efeito, as empresas devem encarar a inovação como de seu cotidiano, da sua cultura. Neste cenário, inserem-se a construção de práticas de inovação baseadas em atividades de pesquisa e desenvolvimento, que podem contribuir para o desenvolvimento tecnológico da indústria, para a geração de diferenciais competitivos e de sua sustentabilidade no mercado (Mesquita et al., 2017).

Neste sentido, o setor de produção de cachaça se apresenta como um campo para o desenvolvimento de diversas inovações (Borges, Lima \& Andrade, 2014; Borges \& Takemoto, 2019), embora seja ainda um setor pouco explorado do ponto de vista científico na administração (Paiva, Andrade, Antonialli \& Brito, 2018). A cachaça, bebida tipicamente 
brasileira, refere-se à denominação típica e exclusiva da aguardente de cana produzida no Brasil, com graduação alcoólica entre $38 \%$ e $48 \%$, obtida a partir da destilação do caldo fermentado da cana-de-açúcar. Ao longo dos últimos anos, podem ser observados movimentos que indicam um processo de conquista de maior prestígio e de melhor imagem da cachaça, levando a uma popularização da bebida junto a diferentes segmentos de mercado (Espartel, Barcellos \& Goularte, 2011; Villar \& Walter, 2017; Andrade, Brito, Brito, Paiva, 2019). Ademais, a cachaça vem se destacando por sua qualidade e pela ação empreendedora de produtores (Lima, 2013; Paiva et al., 2018).

Diante desse contexto, e da importância da inovação para esse tipo de organização, tem-se o seguinte problema de pesquisa: que inovações podem ser observadas no contexto de uma organização produtora de cachaça artesanal? Para responder este questionamento, o presente trabalho tem como objetivo geral identificar a construção de inovações em uma organização do setor de cachaça artesanal situada na região norte do estado de Minas Gerais. Especificamente, buscou-se recuperar a história da empresa e averiguar as diferentes inovações radicais e incrementais que se manifestam no alambique, com foco nas práticas de produção e comercialização de cachaça. Para tanto, fez-se recurso ao método de estudo de caso de natureza qualitativa, estruturado por meio da realização de entrevistas junto ao empreendedor fundador e gestores do negócio. Espera-se, com a realização deste trabalho, que seja possível o estabelecimento de meios para se problematizar as especificidades dos diferentes tipos de inovação observadas no alambique estudado, ressaltando como estas podem contribuir para a configuração de diferenciais competitivos da organização em seu mercado de atuação. Com isso, busca-se gerar evidências sobre as inovações desenvolvidas no referido setor, contribuindo assim para o avanço dos estudos na área e para um melhor entendimento das práticas de empreendimentos inseridos neste contexto.

\section{$2 \quad$ Referencial Teórico}

A palavra inovação é derivada do latim innovatio, e se refere a tornar algo novo, renovar, recriar, reestabelecer (Manual de Oslo, 2005). O conceito de inovação é bastante amplo e permite diversas colocações na busca de uma definição mais específica para cada tipo de situação. A inovação, no contexto empresarial, consiste na exploração de novas ideias para melhorar os negócios, na busca pelo estabelecimento de uma cultura inovação (Mambrini et al., 2011; Bruno-Faria \& Fonseca, 2014), e na busca por de vantagem competitiva (Mesquita et al., 2017). Ela pode ser realizada pela empresa de forma individual ou através de parcerias com outras instituições (Mesquita et al., 2013). A inovação também consiste no processo de adaptação de ideias ou de introdução de melhorias contínuas nas empresas (Freitas, Filardi, Lott \& Braga, 2017). Inovações, por mais simples que sejam, podem necessitar de recursos financeiros ou mobilização de recursos humanos e organizacionais. Por isso, são necessárias análises dos possíveis retornos que a organização poderá ter com esses processos, de modo a avaliar criticamente a sua viabilidade (Tidd \& Bessant, 2015).

De acordo com a Organização de Cooperação e de Desenvolvimento Econômico (OCDE), a inovação é capaz de promover o desenvolvimento de uma nação (OCDE, 2015). As atividades de inovação podem ser consideradas científicas, tecnológicas, organizacionais, financeiras e comerciais. Nas empresas, a natureza dessas atividades varia de forma 
significativa em relação a outras. Enquanto algumas têm processos de inovação bem definidos, outras realizam melhoramentos contínuos em seus produtos, processos ou operações. Em ambos os casos, as empresas que empregam essas práticas são definidas como inovadoras (Manual de Oslo, 2005).

As atividades de inovação podem ser definidas como o conjunto de etapas científicas, tecnológicas, organizativas, financeiras e comerciais, incluindo os investimentos em novos conhecimentos, que levam ou que tentam levar à implementação de produtos e processos novos ou melhorados (Mesquita et al., 2017). A inovação de produto é aquela implementada e introduzida no mercado com produtos tecnologicamente novos ou aprimorados. Já a inovação de processo consiste na adoção de novos métodos de produção durante toda cadeia produtiva, incluindo a forma de entrega do produto final. Esses métodos consistem em mudanças no equipamento ou na organização da produção. (Manual de Oslo, 2005).

A inovação organizacional consiste no desenvolvimento de um método nas práticas de negócios de determinada empresa, seja na forma como o trabalho é realizado dentro dela, até sua forma de lidar com relações externas. A inovação organizacional nas empresas inclui a introdução de estruturas organizacionais significativamente alteradas; a implantação de técnicas de gerenciamento avançado e a implantação de orientações estratégicas novas ou substancialmente alteradas. A inovação em marketing ou modelos de negócio, por sua vez, ocorre quando são adotados ou desenvolvidos novos métodos de marketing e comercialização, com mudanças significativas na concepção do produto, no seu design, na sua embalagem, na promoção ou fixação de preços do mesmo (Manual de Oslo, 2005).

Diante da perspectiva de que todas as inovações devem conter algum tipo de novidade, podem ser aplicados três conceitos para a novidade das inovações: nova para a empresa, nova para o mercado e nova para o mundo. Em se tratando da empresa, pode ser um novo método de produção, um novo processo, uma nova abordagem do marketing ou um novo método organizacional (Schumpeter, 1997). Nesses casos, independentemente de já terem sido implantadas em outras empresas ou de estar sendo apenas aplicada uma melhoria organizacional, trata-se de uma inovação (Freitas, Filardi, Lott \& Braga, 2017). Quando se fala de inovação 'nova para o mercado', há uma referência a empresas que são pioneiras em uma dada ideia, isto é, as primeiras a introduzi-la no mercado em relação aos seus concorrentes diretos locais e/ou regionais. Já a inovação "nova para o mundo" ocorre quando a empresa é a primeira a introduzir a ideia em todos os mercados e indústrias, nacionais ou internacionais. Aqui acontece um grau de novidade extremamente maior do que quando a inovação é nova apenas para o mercado (Manual de Oslo, 2005).

Apesar da variedade de conceitos presentes na literatura sobre inovação, pode-se assumir como base para a discussão os conceitos definidos por Schumpeter (1997). O autor afirma que a inovação pode apresentar-se de cinco formas: $\left(1^{\circ}\right)$ um novo produto, ou a inserção de uma nova qualidade em um produto já existente; $\left(2^{\circ}\right)$ um novo método de produção ou um novo método de tratamento comercial de uma commodity; $\left(3^{\circ}\right)$ a criação de um novo mercado; $\left(4^{\circ}\right)$ a descoberta de uma nova fonte de matéria-prima; $\left(5^{\circ}\right)$ o estabelecimento de uma nova posição em um dado setor. Tal concepção orienta de forma significativa a pesquisa e a produção científica em inovação, demonstrando possibilidades para a construção de conhecimento e compreensão e explicação de especificidades da realidade da inovação em organizações (Freitas et al., 2017). 
De acordo com Burgelman, Christensen e Wheelwright (2012), existem dois tipos fundamentais de inovação: $\left(1^{\circ}\right)$ a inovação radical, caracterizada quando uma organização introduz algo totalmente novo no mercado, promovendo mudanças em termos tecnológicos, estruturais e competitivos e revolucionando disruptivamente os padrões estabelecidos em uma determinada indústria; $\left(2^{\circ}\right)$ a inovação incremental, que envolve iniciativas de introdução de melhorias em produtos, serviços, processos e tecnologias, isto é, um exercício de melhoria contínua, que procura solucionar problemas que foram detectados em um dado produto/serviço, contribuindo para a manutenção e sustentabilidade de vantagens competitivas da empresa no mercado em que atua. Este desenvolvimento conceitual, embora parcialmente consistente com a proposição de Schumpeter (1997), revela uma proximidade maior com a realidade e o cotidiano das empresas, uma vez que leva em consideração a dinâmica, a evolução e o desenvolvimento dos processos de inovação, haja vista sua complexidade e importância no atual cenário econômico e competitivo. Com isso, verificamse diferentes focos de estudo sobre o tema, e diferentes possibilidades a serem exploradas por pesquisadores interessados em compreender essa problemática.

Neste cenário, cumpre destacar a relevância da discussão sobre inovação no contexto de organizações produtoras de cachaça artesanal. O estudo efetuado por Borges, Limas e Andrade (2014) procurou averiguar a construção de práticas de inovação em uma empresa do setor de produção de cachaça artesanal. A organização estudada, situada em uma cidade de médio porte da região do Triângulo Mineiro, estado de Minas Gerais, desenvolveu práticas de inovação variadas, que se associam a elementos de produto, processo e mercado a partir de uma perspectiva de inovações mais radicais e de inovações mais incrementais. Os autores verificaram ainda que tanto as inovações radicais como as inovações incrementais são executadas e desenvolvidas de modo conjunto e contínuo, formando um equilíbrio entre ações que, em última análise, contribuíram para a sobrevivência do negócio e para a sua competitividade no mercado. Logo, diante do exposto, Borges, Lima e Andrade (2014) concluíram a inovação pode e deve ser analisada no contexto de organizações produtoras de cachaça artesanal, um objeto de estudo que merece ser alvo de novas pesquisas para a compreensão e explicação do referido fenômeno.

Paiva et al. (2018) identificaram diferentes práticas empreendedoras voltadas à certificação da cachaça artesanal em uma organização situada na região central do estado de Minas Gerais, e como essas práticas promoveram mudanças nas estratégias do alambique estudado ao longo do tempo. Os autores observaram que foram estruturadas diversas práticas empreendedoras e inovadoras na organização em uma perspectiva coletiva. Essas práticas, cada uma ao seu modo, foram orientadas por uma estratégia de certificação da cachaça, o que exigiu dos empreendedores uma série de mudanças e inovações em termos de produção e comercialização da cachaça, visando alcançar todo o potencial mercadológico gerado pela certificação da bebida. Paiva et al. (2018) concluíram que a teia de práticas empreendedoras e inovadoras desenvolvidas pelos membros da organização estudada convergiram não só para o sucesso da estratégia de certificação, mas também para a própria renovação estratégica do negócio e para a definição de sua posição de competitividade no mercado da cachaça.

Por sua vez, o estudo de Borges e Takemoto (2019) procurou averiguar o desenvolvimento de inovações em um alambique de produção de cachaça artesanal, localizado na região do Alto Paranaíba, estado de Minas Gerais. A pesquisa de campo 
empreendida viabilizou a identificação de um conjunto de práticas de inovação radical e incremental, associadas a iniciativas como o desenvolvimento de novos produtos e a introdução de melhorias de qualidade nos produtos já existentes, como a adoção de novos processos no sistema de produção e a introdução de melhorias nos processos já empregados, e como a exploração de novos mercados e o foco em nichos de mercados já explorados. Com isso, os autores concluíram que as práticas de inovação radical e incremental, quando colocadas em perspectiva, contribuíram de forma importante para a competitividade do alambique estudado, permitindo à empresa renovar suas estratégias de atuação no mercado.

Portanto, através das diferentes abordagens conceituais sobre inovação, e a partir da identificação de estudos anteriores específicos o referido tema, é possível constatar a relevância das discussões sobre os diferentes tipos de processos, práticas e desenvolvimento de inovações no âmbito da produção e comercialização de cachaça artesanal. Trata-se, pois, de não só reconhecer a importância do estudo da inovação e suas ramificações para o entendimento do funcionamento de empresas que buscam crescimento e vantagem competitiva em uma perspectiva mais ampla, mas também de valorizar a compreensão de como cada processo de inovação em especial pode surgir, levando-se em consideração a adoção de novas práticas ou o aprimoramento daquelas que já estão sendo desempenhadas em um dado setor de atividades, e também os benefícios e resultados oriundos desses processos. Evidentemente, este é o caso da produção e comercialização de cachaça artesanal no Brasil, uma atividade que, embora explorada sob a ótica da inovação de diferentes maneiras em outras investigações, apresenta evidências particularizadas a cada realidade analisada e que merece ser melhor compreendida do ponto de vista científico. Sendo assim, este trabalho busca agregar evidências para a compreensão da inovação em organizações produtoras de cachaça, através do estudo do caso de um alambique situado na região Norte de Minas Gerais.

\section{$3 \quad$ Procedimentos Metodológicos}

O presente estudo fundamenta-se em uma abordagem qualitativa de investigação (Flick, 2013), voltada à compreensão da construção de inovações em uma organização do setor de cachaça artesanal, situada na região Norte do estado de Minas Gerais. Enquanto estratégia de pesquisa, foi utilizado o estudo de caso de natureza qualitativa. De acordo com Stake (2000) estudos de caso envolvem investigações que procuram apresentar o que é comum e o que é particular em um caso, contemplando a natureza do caso, seu contexto histórico, o contexto institucional, e os informantes associados ao caso. Neste sentido, o caso é analisado em profundidade, seu contexto é examinado, suas atividades detalhadas, sempre tendo em perspectiva o objetivo maior da pesquisa (Stake, 2000).

Como unidade de análise, foi estudado o caso de uma empresa do setor de cachaça artesanal que atua na região do Norte do estado de Minas Gerais. Trata-se de uma região de destaque nacional na produção de cachaça, com a presença de alambiques tradicionais e já consolidados no mercado. Neste sentido, o caso estudado foi selecionado em função de sua atual posição de liderança na produção de cachaça artesanal no contexto analisado, destacando-se em termos de volume produzido da bebida e de participação de mercado, além de se constituir como uma organização inovadora e com amplo emprego de tecnologia ao longo de seus processos de produção e comercialização. 
Para a coleta de dados, optou-se pelo emprego do método de entrevistas, devidamente orientadas por um roteiro. O instrumento de coleta foi composto por questões abertas, dando liberdade ao entrevistador para arguir sobre os temas e categorias abordados na pesquisa e devidamente informados pelos objetivos da investigação. $O$ roteiro compreendeu os seguintes tópicos de investigação: a) resgate da trajetória histórica da empresas estudada, apontando para eventos como a fundação, o surgimento e a caracterização da organização produtora de cachaça artesanal; b) recuperação da evolução e crescimento da empresa ao longo do tempo, apontando para elementos estratégicos, competitivos e de mercado; c) recuperação das diferentes inovações que ocorreram e ocorrem no alambique, problematizando tanto os processos de criação da organização estudada como seus processos de renovação, em termos da criação e renovação de produtos, processos, métodos e demais práticas associadas à produção e à comercialização de cachaça.

Foram realizadas seis entrevistas junto a atores-chave do negócio, tais como o empreendedor fundador, o diretor comercial, a diretora financeira, o gerente de produção e a gerente de envasamento, como demonstra o Quadro 1. As entrevistas, realizadas de modo presencial, foram previamente agendadas com os entrevistados e tiveram duração média de 65 minutos, sendo gravadas através do uso de gravador eletrônico de áudio, o que viabilizou a transcrição do inteiro teor do conteúdo narrado e registrado nos encontros entre pesquisadores e entrevistados, garantindo assim a precisão dos dados coletados. Cumpre destacar que os dados apresentados a seguir, incluindo o nome da empresa e dos entrevistados, foram suprimidos para garantir o anonimato dos respondentes e o sigilo das informações coletadas.

\begin{tabular}{cllc}
\hline Código & Entrevistado & \multicolumn{1}{c}{ Cargo } & Duração \\
\hline E1 & Entrevistado 1 & Empreendedor-Fundador & 106 minutos \\
E2 & Entrevistado 2 & Empreendedor-Fundador & 33 minutos \\
E3 & Entrevistado 3 & Diretora Financeira & 86 minutos \\
E4 & Entrevistado 4 & Diretor Comercial & 65 minutos \\
E5 & Entrevistado 5 & Gerente de Produção & 82 minutos \\
E6 & Entrevistado 6 & Gerente de Engarrafamento & 14 minutos \\
\hline
\end{tabular}

Quadro 1: Relação dos indivíduos entrevistados

Fonte: Elaborado pelos autores

Por fim, cabe ressaltar que os dados coletados foram tratados com base na técnica de análise de narrativas. Chase (2005) defende que a análise de narrativa constitui uma técnica relevante no âmbito da pesquisa qualitativa, caracterizada como um conjunto de perspectivas que permite apreender histórias sobre indivíduos e as situações que estes vivenciam. Assim, a análise de narrativa, enquanto uma técnica de análise voltada para o estudo das narrativas realizadas pelos sujeitos de pesquisa sobre determinada realidade e/ou experiência vivida, permite o registro, a identificação, a sistematização e a compreensão da história de empresas, incluindo aí a apreensão das diferentes inovações observadas no contexto organizacional (Dawson \& Hjorth, 2012). Neste cenário, procurou-se identificar, no conjunto de material empírico coletado, evidências que pudessem ser associadas tanto às trajetórias de criação e desenvolvimento do negócio estudado, como às diferentes inovações radicais criadas e as diferentes inovações incrementais delas decorrentes. Com isso, foi possível apreender, a partir das narrativas dos entrevistados, as diferentes inovações desenvolvidas no alambique analisado, observadas nas discussões apresentadas a seguir. 


\section{$4 \quad$ Resultados}

A presente seção apresenta os principais resultados da pesquisa. Inicialmente, apresentase a história da empresa. Posteriormente, são identificadas as principais práticas de inovação praticadas pela organização estudada, variando entre inovações radicais e inovações incrementais. Para fins de classificação, as marcas dos produtos produzidos no alambique objeto deste estudo foram substituídas pelos rótulos Marca Alfa, Marca Beta e Marca Gama.

\subsection{História da empresa}

A empresa estudada produz cachaça desde meados de 1974 em Salinas, na região norte do estado de Minas Gerais, popularmente conhecida como Capital Mundial da Cachaça. Em 2012, a cidade de Salinas recebeu o Selo de Indicação Geográfica do Instituto Nacional da Propriedade Intelectual (INPI), por conter clima e solo adequados para o cultivo da cana de açúcar e para a produção da bebida. Cumpre destacar, neste momento, a mudança de percepção do público sobre a cachaça. Anteriormente conhecida como "pinga", a cachaça passou a ser vista como uma bebida de grife e alta qualidade, através do segmento de cachaças artesanais.

O fundador da empresa estudada é visto como uma inspiração para muitos: através de suas ideias empreendedoras, sua gestão visionária e sua incessante vontade de crescer no segmento, conseguiu transformar um pequeno alambique em um dos principais produtores de cachaça do Brasil. A história da empresa passa pelo processo de criação do negócio, e pela definição de estratégias para produzir e comercializar o produto, buscando sempre o crescimento e espaço no mercado regional, nacional e global:

(...) Eu comecei comprando cachaça e vendendo à granel. Depois, eu passei a comprar cachaça em Taiobeiras e envelhecia, engarrafava e vendia tudo. (...). Aí, um sujeito daqui de Salinas quebrou e tinha uma fábrica de cachaça montada (...). E aí, ele resolveu vender a fazenda. Mas eu não tinha condições financeiras... O que eu fiz? Aí eu fui e troquei a casa que eu morava na fazenda e na fábrica de cachaça. Aí é que deu um impulso fora do comum (...). Eu já comprei a fazenda com a fábrica montada, (...) e registrei como [Cachaça Alfa]. (Fundador, E1)

O processo de criação do negócio ocorreu devido à visão empreendedora do fundador. Influenciado pelo sogro, o empreendedor visualizou uma boa oportunidade de negócio no ramo da cachaça. A partir disso, o fundador procurou estruturar o empreendimento através da definição do tipo de cachaça a ser produzida, da busca constante por melhorias no processo produtivo, do aumento da quantidade produzida, e do desenvolvimento e exploração de diferenciais competitivos, como melhorias no plantio e no processo de envelhecimento da bebida:

(...) quando eu comecei a namorar com a minha esposa o pai dela era produtor de cachaça (...). Aí o que ele fazia: ele levava barris de cachaça para Montes Claros, vendia numa F-350 e trazia dois ou três sacos de dinheiro e ele levava uma semana contando esse dinheiro. E ele foi me contou, e eu prestei atenção e falei: é um dos bons negócios que eu posso mexer. E através do meu ex-sogro, aí eu comecei a comprar cachaça em Taiobeiras na safra trazia e estocava, envelhecia e vendia para 
Taiobeiras mesmo na entressafra, assim é que começou a [Cachaça Alfa]. Depois de alguns anos eu resolvi registrar a firma e comecei a engarrafar, engarrafava com um funil, engarrafava na mangueira na boca no funil e vendia uma duas no máximo cinco caixas por mês. Hoje, não. É uma engarrafadora completa e hoje nós batemos a meta numa faixa de dezoito a vinte e cinco mil caixas por mês. (Fundador, E2)

(...) Aí meu pai pegou e começou a produzir, era uma produção pequena de 1200 L/dia, 600 L, começou com 600 e depois foi para 1200. Aí, a empresa foi crescendo, assim, hoje a gente vê que junto com o empreendedorismo dele e a visão comercial que ele tinha, o "marketeiro" que ele é, que deu um diferencial para a [empresa]. (...) hoje eu creio que a [Cachaça Alfa] vende mais de $70 \%$ do mercado de cachaça artesanal de Salinas. A gente tem mais uma ou duas concorrentes, mas a concorrente mais forte que a gente tem hoje (...), enquanto a gente vende 25 mil dúzias, eles devem vender 17, 16, 15, entendeu? Então hoje, em cachaça artesanal (...) eu acho que a [empresa] desponta dentro de Minas Gerais. Aí como que isso aconteceu: começamos a produzir, aumentar, aí abrimos uma praça em Belo Horizonte (...) depois, Belo Horizonte começou a se consolidar, começou a distribuir, aí vieram os mercados, veio Brasília, veio São Paulo, veio Rio, e aí começou. (Diretora Financeira, E3)

A partir desse cenário inicial, verifica-se a configuração de uma trajetória constante de evolução da empresa estudada, o que permite a ela estruturar decisões e ações voltadas ao desenvolvimento de suas atividades de produção e comercialização, formando um diferencial competitivo e abrindo espaço para a empresa no mercado de cachaça. Esse período de evolução e crescimento foi marcado pela mudança da imagem do produto, pela abertura de mercados em outros estados como Rio de Janeiro, São Paulo, Espírito Santo, Bahia, Goiás, além do Distrito Federal, pela formação de uma equipe comercial, pelo estabelecimento de parcerias com times de futebol, e pela definição de campanhas de marketing.

Essa nova realidade demandou com que novos investimentos em plantios e em instalações de produção fossem efetuados, levando o alambique a um novo patamar de produtividade. Houve, diante disso, novas necessidades de investimentos em produção, qualidade, pessoal, e gestão, transformando o outrora pequeno alambique em uma "empresa produtora de cachaça artesanal em escala industrial", com foco em tecnologia, qualidade, produtividade e eficiência. A partir desse cenário, a organização passou a atuar em praticamente todos os estados brasileiros e também exportação para os Estados Unidos e a União Europeia, com alto nível de profissionalização da produção e da gestão, fornecendo aos consumidores cinco marcas distintas, com focos que variam desde o segmento Premium até camadas mais populares, sendo inclusive premiada em diversas feiras especializadas e detentora de altas classificações em rankings elaborados pela imprensa brasileira.

Portanto, a história da empresa estudada é marcada pela construção de novas oportunidades de negócio e pela busca constante por inovações, situações que por sua vez contribuem para a consolidação da empresa no mercado e todo o sucesso respectivo a ela. Com base nisso, tem-se a necessidade de descrever e compreender todos esses elementos, de modo a permitir identificação de processos de inovação radical e de inovação incremental.

\subsection{Inovação Radical}


A inovação radical diz respeito à mudanças significativamente diferentes em produtos, serviços ou processos (Tidd \& Bessant, 2015). Neste contexto, observa-se práticas de inovação radical em diversos momentos da trajetória da empresa, incluindo inicialmente perspectivas de inovação de processo:

(...) há 40 anos atrás, [o fundador] comprava em uma cidade vizinha aqui. Comprava 400 litros de cachaça, 1000 litros, e revendia, vendia para a própria cidade a cachaça envelhecida. Aí ele pensava: 'eu estou ficando é besta? Invés de comprar cachaça, eu vou é produzir ela e envelhecer'. Aí ele começou a fazenda, começou a fazer cachaça, parou de comprar lá. Aí ele pegou e começou a fazer mais ou menos 100 litros de cachaça por dia, e aí o pessoal começou a vender. Aí o pessoal ficou procurando muito pra comprar e ele ainda brincava com os funcionários que um dia ele iria fazer 1000 litros de cachaça, e eles falavam: 'o Sr. é doido? Não tem como fazer 1000 litros de cachaça'. (...). Aí quando vê o [fundador] fez 1000 litros de cachaça. Aí ele falou: 'um dia eu faço 10 mil'. Aí há mais ou menos uns 4, 5 anos atrás um cara falou '10 mil litros de cachaça é bebida, é cachaça demais'. Quando você vê hoje, já tá produzindo 15 mil, 20 mil por dia. (Gerente de Produção, E5)

Em 1975 eu já comecei a colher cana. Antes, eu plantava cana em cova, hoje a gente planta em soco. Então uma área que plantava em cova dava uma certa quantidade de tonelada e hoje dá dez vezes mais a produção de tonelada em soco. E eu transportava do canavial para o engenho em burro com cangaia, depois foi evoluindo... E era fornalha com fogo direto, depois passou a carro de boi, transportado por carro de boi, depois passou para trator em carreta pequena e hoje tem diversos tratores com carretas de dez toneladas. E hoje nós temos também uma caldeira que não é fogo direto e tem uma instalação com dornas grandes de cinquenta mil litros de fermentação e onze alambiques funcionando (Fundador, E1).

Um dos desafios pra produzir cachaça em Salinas era a falta de chuva, que diminuiu muito. Então nós começamos a catar água do rio. Só que molhar é uma coisa, irrigar é outra, e chuva é outra ainda. Então, pra molhar você coloca a quantidade de água que você tem disponível; pra irrigar, você coloca a quantidade de água que a cana necessita. Então são duas diferenças. Como foi diminuindo as chuvas, e tirar água do rio não ajuda em nada, hoje nós temos seis poços artesianos para irrigar as canas. Nós estamos fazendo uma barragem para captar a água de chuva e ter quatrocentos milhões de litros de água, pra justamente na época da seca a gente poder irrigar. Esse foi um desafio. Outro também foi o tamanho da indústria, que cresceu muito. A gente carregava cana nos braços e hoje tem uma carregadeira. A gente pegava as caixas e punha no caminhão, hoje tem uma empilhadeira. (...). Eu não paro de investir não, já tem planos para frente que eu vou ampliar mais ainda e mecanizar (...), mas sem deixar de ser artesanal. Nós produzimos em grande escala, mas não saindo das características da cachaça artesanal. (Fundador, E2)

As narrativas ilustram a elaboração de práticas de produção que podem ser reinterpretadas a partir de diferentes inovações desenvolvidas no âmbito do processo produtivo de cachaça no alambique estudado. Há, por parte dos entrevistados, uma preocupação central em estabelecer uma atividade produtiva mais eficiente, dada a demanda pela bebida e a necessidade de uma quantidade maior de produto e de matéria-prima para o beneficiamento da mesma. Para tanto, foram realizadas algumas mudanças e inovações ao longo do processo de produção, de modo a viabilizar essa estratégia de atuação da empresa no mercado. Iniciativas como alterações na forma de plantio de cana-de-açúcar, como o uso de 
irrigação da área plantada, como a utilização de máquinas para o transporte da cana do campo para a fábrica, como a ampliação da capacidade de moagem, como a adoção de máquinas e equipamentos para as etapas de processamento e engarrafamento da bebida, como o uso de dornas com grande capacidade de armazenamento e vários alambiques para a destilação da cachaça, dentre outras, visam exatamente prover à organização um nível maior de mecanização e, consequentemente, uma produção em grande escala industrial.

No entanto, apesar dessas inovações, que reorientam o processo produtivo enquanto um processo mecânico, industrial, a empresa não abandona as características da cachaça artesanal, trabalhando com processo de fermentação natural, baseado no uso de levedura selvagem. Isto posto, tem-se a configuração de um processo de produção de cachaça artesanal em escala industrial, estabelecendo uma inovação radical em termos de processo, especialmente por ser uma prática praticamente inexplorada por outros produtores no referido setor. Aliado a esse cenário de inovação radical de processo, tem-se igualmente a configuração de práticas que se associam a inovações radicais de produto, com a criação de novos produtos e novas linhas de cachaça artesanal:

A [Cachaça Beta] é curtida em bálsamo, e a [Cachaça Alfa], um produto novo, curtida em umburana, totalmente diferenciado um do outro, e diferente da maioria das cachaças da nossa região. O envelhecimento da [Cachaça Beta] é em bálsamo, e a [Cachaça Alfa] é em umburana. Então ela tem um gosto totalmente diferente, e a gente hoje sabe que é por causa disso, por causa do envelhecimento, que se vende mais a [Cachaça Alfa], entendeu? Mas em questão de, por exemplo, a [Cachaça Alfa], hoje a gente vende mais, mas na hora que ela vai para os degustadores, $\mathrm{N}$ marcas para serem degustadas, quem fica na frente é a [Cachaça Beta], o paladar da [Cachaça Beta] para os degustadores, ele é mais preferido. Então, a gente tem essa distância aí. Eu vejo hoje, 90\% da minha venda da empresa, é [Cachaça Alfa], 10\% é [Cachaça Beta], mas na hora que eu vou para um know-how de classificação, dos entendedores lá, a [Cachaça Beta] sai na frente da [Cachaça Alfa], entendeu? (Diretora Financeira, E3)

(...) criamos a [Cachaça Gama], que é uma cachaça de um litro, uma garrafa clara, uma cachaça com teor [alcóolico] um pouco menor e branca, envelhecida em tonel de jequitibá, pra se fazer drinks, e que tem saído muito. Foi uma pesquisa de muito tempo. A gente observou que a cachaça gelada, hoje, ela sai mais. Existe um consumo muito alto desse tipo de mercado, igual a caipirinha, igual a questão da cachaça com limão, alguns drinks já diferenciados que a gente tem hoje, então assim, isso está fazendo o consumo aumentar muito. (...). Isso está dando certo porque está evoluindo muito uma classe que não consumia. (...). A gente tem feito alguns estudos, até mesmo de marketing, que a cachaça ela evoluiu muito no meio de mulheres. Mulher não consumia cachaça. Quem consumia cachaça, 90\% eram homens, e isso está mudando, esse tabu está se quebrando, e a gente está conseguindo entrar, e com um resultado muito positivo. (Diretora Financeira, E3)

A construção de uma estratégia de segmentação de produto e envelhecimento de cachaça repercute na criação de três produtos distintos: a cachaça aqui denominada como "Cachaça Beta", envelhecida em tonéis de madeira de bálsamo, segue longa tradição das cachaças produzidas em Salinas; já a cachaça aqui classificada como "Cachaça Alfa", é envelhecida em tonéis de madeira de umburana, e se configura como um "produto novo", "diferente da maioria das cachaças da região" de Salinas. Além disso, a "Cachaça Gama" 
refere-se a uma bebida voltada exclusivamente para a produção de drinks. Esse produto, definido a partir de uma garrafa diferenciada, contém uma bebida transparente, com teor alcóolico reduzido, armazenada em tonel de madeira de jequitibá, posicionada no mercado para atender a um público que não consome cachaça, notadamente o público feminino.

Assim, são constituídas inovações radicais de produto, a partir da definição de dois produtos com estratégias de envelhecimento que diferenciam ambas as marcas da bebida, e através da caracterização de um tipo particular de cachaça com menor graduação alcóolica, para maior aceitação junto ao público em geral e para diferenciá-las das outras cachaças produzidas na cidade de Salinas. Trata-se, portanto, de inovações que podem ser reinterpretadas como práticas inovadoras que extrapolam a mera definição de uma segmentação de produto, sobretudo por estabelecerem toda uma estratégia de entrada da bebida no mercado, de envelhecimento da cachaça, e de redução da graduação alcóolica. Essas práticas, por sua vez, permitem o desenvolvimento de estratégias que visam garantir um diferencial competitivo da empresa no mercado, através de inovações radicais de mercado e comercialização de cachaça:

(...) A gente busca cada vez mais um mercado selecionado. A [Cachaça Alfa] hoje, você pode ver, Rock in Rio, tem a cachaça aí a Rock in Rio, o que vende lá é a nossa cachaça. A [empresa] tem convênio com o Cruzeiro, Corinthians, Fluminense, Atlético, Palmeiras, São Paulo e Corinthians. E tem um trabalho muito grande, a [empresa] também tem muita venda aí, por exemplo, em evento, você quer fazer um evento, aí ela tem garrafinha pequena, ela produz muita cachaça desse tipo, personalizada. (Diretor Comercial, E4).

A gente investe muito em questão de publicidade mesmo, entendeu? Em mídia pesada. A gente tem uma área forte nisso que é o departamento de marketing, e com isso a gente vai em um show, a uma revista, uma televisão, a um jogo de futebol, que tem um aspecto muito positivo pra nossa venda girar, entendeu? Por último agora, a gente esteve no Rock in Rio, e a gente fechou uma parceria com a [fábrica de chocolate], que em volumes financeiros, não é grande, mas em valor agregado pra marca. Foi pro dia dos pais, eles fizeram uma embalagem com uma garrafinha da [marca Alfa] pequena, e com o chocolate deles pra pessoa presentear no dia dos pais, foi uma campanha. Então assim, é um produto agregado, eles escolheram a [marca Alfa], como uma marca forte, pra poder estar usando junto com o produto deles, como presente pro dia dos pais. Então assim, foi uma campanha que surpreendeu a gente, pela repercussão de mídia que ela deu no Brasil todo. (Diretora Financeira, E3)

Os relatos dos entrevistados ilustram diferentes decisões a ações voltadas para a atuação da empresa no mercado. Com o passar do tempo, foram observadas iniciativas de divulgação do produto em ambientes ainda inexplorados, vinculadas com estudos realizados na área de marketing. Trata-se, pois, de um processo de inovação radical que merece ser destacado, visto que o fundador sempre buscou oferecer novidades aos seus clientes e divulgar a marca para o constante crescimento da empresa no mercado.

Tem-se, em síntese, diferentes situações de inovação radical, que podem ser observadas em termos de processo, produto, e mercado, e que contribuem para a competitividade da empresa estudada e para o estabelecimento de diferenciais em seu setor de atuação. Essas práticas inovadoras foram norteadas, em maior ou menor grau, por uma certa 
obsessão por crescimento de mercado, viabilizado com base na exploração do conceito de produção de cachaça artesanal em escala industrial, e ilustrado a partir das diferentes iniciativas dos entrevistados envolvidos na gestão estratégica do negócio. Não obstante, apesar de sua relevância para o contexto organizacional, tais práticas inovadoras não se alinham apenas a situações específicas de inovação radical, mas também contemplam iniciativas que podem ser interpretadas enquanto práticas de inovação incremental.

\subsection{Inovação Incremental}

A inovação incremental busca encontrar melhorias em produtos ou processos já consolidados. Pode ser visualizada como uma maneira de resolver problemas em que a meta é clara, mas a maneira de chegar até ela não. Quando a empresa opta por esse tipo de inovação está buscando uma maneira de extrair o máximo de valor possível dos seus produtos ou processos já existentes, sem a necessidade de fazer mudanças significativas ou altos investimentos (Davila, Epstein \& Shelton, 2009). As inovações podem ter diversas implicações, desde inovações radicais, que geram mudanças expressivas no mercado através da criação de novos produtos, serviços ou tecnologias, ou inovações incrementais - que englobam a introdução de progressos contínuos em produtos, tecnologias ou serviços já existentes (Lounsbury \& Crumley, 2007). Neste caso, a inovação incremental de produto ocorreu quando o empresário observou a composição das cachaças fabricadas na região e decidiu diminuir a graduação alcóolica:

(...) Nós inovamos, por exemplo, ao abaixar a graduação alcoólica. Eu não sei te precisar em anos, mas todas as cachaças da região de Salinas, a grande maioria, não digo todas, era com uma graduação em torno de quarenta e oito graus, e nós fomos os pioneiros a abaixar pra quarenta e dois. Hoje, a grande maioria é quarenta e dois. Não muda muito o produto, mas deixa ele mais agradável pro consumidor em geral. (Diretor Comercial, E4)

Quanto a inovação de processos, Tidd e Bessant (2015) define a inovação incremental como mudanças na forma como o produto ou serviço são produzidos, entregues e designados. Neste sentido, uma das questões que podem ser observadas envolve a delimitação da produção em termos conceituais de qualidade:

(...) A gente carregava cana nos braços hoje tem uma carregadeira, a gente pegava as caixas e punha no caminhão hoje tem uma empilhadeira (...). Antigamente meu engenho era engenho pequeno tocado a motor diesel, hoje é um engenho grande tocado a energia da Cemig (...) O sonho era ter produção própria, um ampliamento da indústria da produção da cachaça, um ampliamento do envelhecimento que foi realizado na engarrafadora e tem outros sonhos que ainda vão realizar como a mudança do escritório e da engarrafadora para outro endereço que vai ficar mais fácil para o acesso dos clientes. (Fundador, E1)

A cachaça artesanal é feita com carinho, com amor e em pequena quantidade. Nós é que crescemos, mas não perdendo a qualidade da cachaça artesanal. Você pode ver que nós ainda temos princípios, nós melhoramos a qualidade, mas a origem nós não perdemos. (Fundador, E2) 
Toda vida a qualidade foi uma grande preocupação. Agora, com o recurso da tecnologia, em especifico os laboratórios, facilitou muito atestar essa qualidade. (...) A nossa cachaça, toda ela é analisada, os lotes, dentro das exigências do Ministério da Agricultura. Nós temos uma pessoa que só é responsável pela homogeneização e pela padronização desses lotes. Esse responsável também tem um gerente que acompanha, e na parte de produção, tem o laboratório e o gerente que acompanha todos os processos pra não sair fora das exigências. (...). No processo, pra você ter uma ideia, de fabricação, tem uma análise de cana, uma análise de caldo, uma análise do vinho e uma análise do destilado. Então desde a matéria-prima lá atrás que é a cana, logo depois da cana é o caldo, a fermentação e a destilação. Aí depois de tudo isso pronto que é armazenado durante um tempo, no momento de preparar o lote ainda tem mais uma pessoa. (Diretor Comercial, E4)

A empresa realizou melhorias no processo produtivo, desde a plantação da cana, a colheita, a produção da cachaça e seu envelhecimento, mantendo o foco na qualidade do produto. Ações e decisões dessa natureza, ao serem analisadas em seu conjunto, se configuram como inovações incrementais que definem, conceitualmente, o diferencial do produto. Essas práticas inovadoras tornam-se evidentes quando investimentos em qualidade se configuram como objeto de decisões estratégicas por parte da empresa e de seus diretores, que orientam diversas ações que visam tanto agregar atributos particulares à bebida como definir procedimentos para atestar essa qualidade. Assim, ao certificar que a cachaça produzida pela organização investigada atende a princípios fundamentais da produção artesanal de qualidade, abre-se espaço para a construção do diferencial do produto no mercado através de inovações incrementais, que também se fazem presentes em termos de mercado e comercialização da bebida:

Na década de 90, (...) a gente começou a estruturar, levar o produto pra novos mercados. [A região de] Salinas tem 26 ou 30 marcas, uma ou duas que disputam. Hoje eu creio que a [empresa] vende mais de $70 \%$ do mercado. A gente tem mais uma ou duas concorrentes (...), mas enquanto a gente vende 25 mil dúzias, eles devem vender 17, 16, 15, entendeu? Então hoje, em cachaça artesanal, como referência na produção (...), eu acho que a [empresa] desponta dentro de Minas Gerais. Como que isso aconteceu? Começamos a produzir, aumentar, aí abrimos uma praça em Belo Horizonte. (...). Depois, Belo Horizonte começou a se consolidar, começou a distribuir. (...) Quando Belo Horizonte firmou mesmo, a gente abriu um televendas como uma vendedora, aí essa vendedora começou a fazer o resto do país, aí com a necessidade a gente chegou a operar com 10, 12 operadoras de televendas, que é o telemarketing, e começou essas praças que estavam se abrindo colocar representantes para consolidar a marca. (...) Aí veio Brasília, veio São Paulo, veio Rio, e aí começou atender nacionalmente. (Diretora Financeira, E3)

A gente assim, com relação aos outros [produtores], se somar todos, eles não conseguem vender 2 mil caixas e a gente está vendendo 25 mil. Fabricando na mesma cidade, com a mesma produção, com as mesmas características. Isso já é um diferencial e uma conquista muito grande que a gente por isso, de ter conquistado essa fatia do mercado. Ela é muito maior, ela não vai parar de crescer entendeu? Mas hoje a gente pensa muito assim, não muito mais crescimento em números, mas em valorização do produto. (Diretora financeira, E3) 
A gente sempre gostou muito de trabalhar com ponto de dose (...) em restaurantes, bares, que é onde realmente tem um contato maior com o cliente. Eu creio que o acontecimento das vendas vem devido a isso (Fundador, E1)

Atualmente, nós já estamos com exportação. Já estamos com carga, com lote, ainda que pequenininho, indo pros Estados Unidos e pra Europa, Portugal principalmente. A gente tá mandando também pra Argentina, Paraguai, outros países da América do Sul... e estamos vendo também de mandar pra Alemanha. (Gerente de Produção, E5)

Com base nessa perspectiva, é possível verificar a inovação incremental na empresa através de melhorias no processo de comercialização. A partir da mudança da imagem do produto, houve a construção de iniciativas que permitiram posicionar a cachaça em novos mercados e consolidá-la em mercados anteriormente explorados. Com isso, houve a abertura de mercados em capitais como Belo Horizonte, Brasília, São Paulo, Rio de Janeiro, Goiânia, Salvador, dentre outras, levando a empresa a adotar procedimentos como o telemarketing, a formação de equipe de representantes comerciais, a definição de ações mercadológicas no chamado "ponto de dose", o licenciamento junto a clubes de futebol, o estabelecimento de parcerias junto a eventos musicais e a campanhas de marketing de outras empresas, dentre outras. Mais recentemente, houve também a exploração de oportunidades de exportação da cachaça para diversos países. Tem-se, então, a formação de iniciativas de comercialização que se configuram como inovações incrementais de mercado, que contribuem para o posicionamento da empresa em relação à concorrência, para o acesso a novos mercados, e para a consolidação da organização enquanto referência na produção de cachaça.

\section{Considerações finais}

O objetivo do presente trabalho constituiu identificar a construção de inovações em uma organização do setor de cachaça artesanal situada na região norte do estado de Minas Gerais. Especificamente, buscou-se recuperar a história da empresa e averiguar as diferentes inovações radicais e incrementais que se manifestam no alambique, com foco nas práticas de produção e comercialização de cachaça. Para tanto, foi realizado um estudo de caso qualitativo, estruturado através de entrevistas junto ao fundador e gestores centrais ao negócio, buscando delimitar a identificação de situações de inovação radical e inovação incremental desenvolvidas no âmbito do empreendimento estudado.

Neste estudo, foi possível observar o desenvolvimento de diferentes processos inovativos vinculados à produção e à comercialização de cachaça artesanal no alambique estudado. De um lado, a inovação radical foi observada na produção artesanal da cachaça em escala industrial, na criação de novos produtos, nas estratégias de marketing e licenciamento e também na estratégia de envelhecimento ainda inexplorada na região. De outro lado, a inovação incremental foi observada na realização de melhorias no processo produtivo, na redução da graduação alcóolica da cachaça, nos avanços no processo de comercialização e no foco em qualidade através da melhoria contínua em seus produtos e processos. Trata-se, portanto, de entender a inovação, no âmbito do alambique investigado, como um movimento amplo e cumulativo, marcado por práticas inovativas diversas que, em maior ou menor grau, permitiram o crescimento do negócio, a melhoria das suas práticas de produção, e o crescimento das suas práticas de comercialização. 
Diante do exposto, conclui-se que a inovação é extremamente importante para o a empresa, contribuindo para sua competitividade. Os processos são desenvolvidos no contexto de uma organização tradicional, mas que, ainda assim, desenvolve diversas práticas inovadoras, pois está competindo em um mercado cuja segmentação é bastante competitiva, que é o segmento premium. Essas práticas, por sua vez, contribuem para sua renovação e longevidade no setor de cachaça, o que por si só reforça a importância do desenvolvimento de inovações radicais e de inovações incrementais em seu contexto de atuação.

Cumpre destacar, no entanto, que o presente trabalho não deixa de apresentar algumas limitações. Primeiro, foi realizado o estudo de caso em uma única empresa, o que limita o alcance dos resultados da pesquisa aqui realizada. Portanto, sugere-se a realização de novos estudos em outras empresas do setor, seja a partir de estratégias de estudos de casos múltiplos, seja através da exploração de métodos quantitativos de investigação. Além disso, observa-se a existência de poucos estudos sobre o tema inovação no contexto de organizações produtoras de cachaça, fato que demanda, como consequência, a realização de estudos adicionais que apliquem o quadro teórico desenvolvido neste trabalho em organizações do setor que se situam em diferentes contextos, como alambiques da região Sul, Sudeste e Nordeste do Brasil, e até mesmo aqueles situados em outras regiões do estado de Minas Gerais.

Não obstante, o presente trabalho apresenta algumas contribuições para o campo de estudos em inovação, pois explora temática importante em um contexto pouco estudado no âmbito acadêmico e científico. Ao gerar novas evidências sobre a inovação no setor de cachaça artesanal, através da observação da construção dinâmica de inovações radicais e incrementais, torna-se possível demonstrar e explicitar como esses processos e práticas vão se desenvolvendo com o passar do tempo no âmbito de empresas do referido setor, formando assim um quadro de análise específico à compreensão e explicação da inovação em cachaçarias artesanais. Em outros termos, as análises realizadas no estudo podem somar à literatura já existente sobre o tema, bem como abrir caminhos para novos estudos que tenham como objetivo aprofundar as vantagens do desenvolvimento e da exploração de inovações em processos produtivos, produtos e mercados, fato que certamente pode contribuir para o avanço do campo de estudos sobre inovações, e para o entendimento da dinâmica e das particularidades que se manifestam em organizações produtoras de cachaça artesanal.

\section{Referências}

Andrade, L. P., Brito, V. G. P., Brito, M. J., \& Paiva, C. M. N. Sociomaterialidade e Estratégia como Prática: a estratégia mercadológica de uma organização produtora de cachaça artesanal. Revista FSA, 16(3), 27-47.

Borges, A. F., \& Takemoto, S. N. C. (2019). Inovação no Setor de Cachaça Artesanal: Estudo de Caso. Revista Pensamento Contemporâneo em Administração, 13(1), 79-99.

Borges, A. F., Lima, J. B. \& Andrade, D. M. (2014). Práticas de inovação em empresa familiar: estudo de caso. Revista Pensamento Contemporâneo em Administração, 8(3), 37-54. Bruno-Faria, M. F., \& Fonseca, M. V. A. (2014). Cultura de inovação: conceitos e modelos teóricos. Revista de Administração Contemporânea, 18(4), 372-396.

Burgelman, R. A., Christensen, C. M. \& Wheelwright, S. C. (2012). Gestão estratégica da tecnologia e da inovação: conceitos e soluções. Porto Alegre: AMGH Editora. 
Chase, S. (2005). Narrative inquiry: multiple lenses, approaches, voices. In N. K. Denzin \& Y. S. Lincoln. (Eds.). Handbook of Qualitative Research. 3a ed. Thousand Oaks: Sage Publications (vol. 1, chapter 25, pp. 651-680).

Davila, T., Epstein, M. \& Shelton, R. (2009). As regras da inovação. Porto Alegre: Bookman. Dawson, A.; Hjorth, D. (2012). Advancing the field of family business research through narrative analysis. Family Business Review, 25(3), 339-355.

Espartel, L. B., Barcellos, M. D. \& Goularte, J. H. (2011). O Mercado da Cachaça da Região Sul do Brasil: um estudo exploratório. Revista Alcance, 18(2), 219-236.

Flick, U. (2013). Introdução a metodologia de pesquisa: um guia para iniciantes. Porto Alegre: Penso.

Freitas, A. S., Filardi, F., Lott, A. C. O., \& Braga, D. (2017). Inovação Aberta nas Empresas Brasileiras: Uma Análise da Produção Acadêmica no Período de 2003 a 2016. Revista IberoAmericana de Estratégia, 16(3), 22-38.

Lima, J. B. (2013). Oportunidades: identificação, exploração e construção de novas oportunidades no processo de exploração da produção da Cachaça em Minas Gerais: o caso da Cachaça Bocaina (Lavras-MG). In: H. P. V. Machado (Org.). Empreendedorismo, Oportunidades e Cultura: seleção de casos no contexto brasileiro. Maringá (vol. 1, cap. 3, p. 67-90).

Lounsbury, M. \& Crumley, E. (2007). New practice creation: an institutional perspective on innovation. Organization Studies, 28(4), 993-1012.

Mambrini, A. B., Cintho, S., Dattein, E. D., Medina, J. A. A., \& Maccari, E. A. (2011). Cultura inovadora na pequena e média empresa. Revista de Gestão e Projetos, 2(1), 26-51.

Manual de Oslo. (2005). Diretrizes para coleta e interpretação de dados sobre inovação. Rio de Janeiro: OCDE/EUROSTAT/FINEP.

Mesquita, D. L., Borges, A. F., Santos, A. C., Sugano, J. Y. \& Veloso, T. C. (2017). Dynamic Capabilities in Automotive Pollutants Reduction Technologies: Case Study. Revista de Administração Mackenzie, 18(3), 15-41.

Mesquita, D. L., Borges, A. F., Sugano, J. Y., \& Santos, A. C. (2013). O desenvolvimento de processos de inovação sob a ótica da teoria dos custos de transação: o caso da tecnologia flexfuel. Revista de Administração e Inovação, 10(1), 119-140.

Paiva, A. L., Andrade, D. L., Antonialli, L. M. \& Brito, M. J. (2018). Strategic Entrepreneurship: observations from the practices of cachaça certification. Revista de Administração Mackenzie, 19(2), 1-24.

Schumpeter, J. A. (1997). Teoria do desenvolvimento econômico: uma investigação sobre lucros, capital, crédito, juro e o ciclo econômico. São Paulo: Abril Cultural.

Stake, R. E. (2000). Case Study. In N. K. Denzin \& Y. S. Lincoln. (Eds.). Handbook of Qualitative Research. London: Sage. (vol 1., chapter 8, pp. 236-247).

Tidd, J. \& Bessant, J. (2015). Gestão da inovação. Porto Alegre: Bookman.

Villar, E. G., \& Walter, S. A. (2017). A Influência do Processo de Clusterização no Crescimento de Pequenas Empresas: Um Estudo de Caso na Indústria da Cachaça de Santa Catarina. Revista de Empreendedorismo e Gestão de Pequenas Empresas, 6(1), 75-100. 